\title{
A implantação dos planos de cultura no estado e na cidade de São Paulo: histórico, construção e desafios ${ }^{1}$
}

\author{
La implementación de planos de cultura en el estado y la ciudad \\ de São Paulo: historia, construcción y desafíos
}

\section{The cultural plans implementation in the state and city of São Paulo: history, construction and challenges}

\author{
Inti Anny Queiroz ${ }^{2}$
}

\section{Palavras-chave: \\ Plano de cultura \\ Cidades \\ Orçamento}

\section{Resumo:}

Os processos de implantação dos planos de cultura nos entes federados são parte relevante da estrutura do Sistema Nacional de Cultura, que depende dos mesmos para compor a descentralização territorial, a diversidade e a lógica de subsidiaridade da proposta. Neste artigo apresentamos um panorama detalhado dessa construção no estado e município de São Paulo com vistas a demonstrar dois processos diferentes que ocorreram na mesma região do país e que em muitos momentos contou com agentes similares, tanto do governo quanto da sociedade civil. Trataremos dos processos a partir da observação histórica, relatando como ocorreram em cada ente federado. Observaremos as atividades e as dificuldades enfrentadas tanto por questões políticas quanto burocráticas e que vem impedindo a plena implantação dos sistemas de cultura territoriais. As atividades promovidas pelos movimentos das militâncias da cultura para tentar reverter as tentativas de desmonte também serão destacadas a fim de compreendermos a arquitetônica e as tensões na composição do sistema.

1 Texto recebido em 17/09/2019 e aceito para publicação em 23/10/2019.

2 Mestre e Doutora em Filologia e Língua Portuguesa pela Faculdade de Filosofia Letras e Ciências da Universidade de São Paulo (FFLCH-USP). Professora do Curso de Extensão em Gestão Cultural da Pontifícia Universidade Católica de São Paulo, Brasil. Contato: inti.queiroz@gmail.com - https://orcid.org/0000-0002-6484-2712 


\section{Resumen:}

Los procesos de implementación de planos culturales en las entidades federadas son una parte relevante de la estructura del Sistema Nacional de Cultura, que depende de ellos para componer la descentralización territorial, la diversidad y la lógica de subsidiariedad de la propuesta. En este artículo presentamos una descripción detallada de la implementación con el fin de demostrar dos procesos diferentes que ocurrieron en la misma región del país y que en muchas ocasiones tuvieron agentes similares, tanto del gobierno como de la sociedad civil. Trataremos los procesos desde la observación histórica, informando cómo ocurrió su construcción en cada entidad federada. Analizaremos las actividades y dificultades que enfrentan, los problemas políticos y burocráticos que han impedido la plena implementación de estos sistemas de cultura territorial. Las actividades promovidas por los movimientos culturales de militancia para tratar de revertir los intentos de desmantelamiento también se resaltarán para comprender la arquitectura y las tensiones en la composición del sistema.
Palabras clave:

Plano de cultura

Ciudades

Presupuesto

\section{Keywords:}

Cultural plan

Cities

Budget

\section{Abstract:}

The implementation process of cultural plans in the federated entities are a relevant part of the structure of the National Culture System, which depends on them to compose the territorial decentralization, diversity and the logic of subsidiarity of the proposal. In this paper we present a detailed overview with the intention to demonstrate two different processes that occurred in the same region of the country and which, in many times, had similar agents, both from government and civil society. We will deal with the processes from the historical observation, reporting how their construction occurred in each federated entity. We will focus in what the activities and difficulties faced by both political and bureaucratic issues that have been impeding the full implementation of these territorial culture systems. The activities promoted by the militancy movements of culture to try to reverse attempts to dismantle will also be highlighted in order to understand the architectonic and tensions in the composition of the system. 


\section{A implantação dos planos de cultura no estado e na cidade de São Paulo: histórico, construção e desafios}

\section{Introdução}

A implantação do Plano Nacional de Cultura nos estados e municípios é parte integrante da lógica do processo do sistema em termos federativos. Compreender como cada região do país tem desenvolvido estes processos pode nos auxiliar não apenas na análise do sistema como um todo, mas principalmente a observar os desafios e problemas estruturais do modelo em termos de gestão pública a nível federal.

Neste estudo buscamos apresentar, a partir da observação histórica e político-cultural da implantação dos Planos de Cultura do estado e do município de São Paulo, como esta construção tem acontecido e quais dificuldades, desafios e soluções foram apresentados, principalmente pela militância da cultura. Iniciaremos a reflexão sobre o estado e em seguida trataremos da cidade. Evidenciaremos não apenas os planos, mas, por conta do caráter sistêmico da arquitetônica do Sistema Nacional de Cultura (SNC), observaremos também os trâmites no legislativo, outros elementos do sistema como as conferências, os conseIhos, os fundos e o orçamento.

\section{A implantação do sistema de cultura no estado de São Paulo}

Desde o início, os processos de construção do Sistema Estadual de Cultura em São Paulo encontraram um cenário não muito propício para sua implantação por conta da falta de interesse da gestão estadual nessa nova Política Nacional de Cultura. Há pouca ou quase nenhuma informação disponível sobre as conferên- cias estaduais de cultura do estado, justamente por conta da falta de interesse do estado na realização desses encontros.

No período do chamado do então Ministério da Cultura (MinC) para a realização das primeiras conferências municipais e estaduais em 2005, visando à $1^{\text {a }}$ Conferência Nacional de Cultura (CNC), o estado de São Paulo não realizou sua primeira conferência estadual (ainda que diversos outros tenham realizado as suas). Em 25 de novembro de 2009, a Secretaria de Estado da Cultura de São Paulo, capitaneada no período pelo secretário João Sayad, promoveu no Memorial da América Latina a $1^{\text {a }}$ Conferência Estadual de Arte e Cultura ${ }^{3}$ para discutir assuntos de interesse da gestão. No dia 26 de novembro de 2009 , ocorreu o que seria a $1^{\text {a }}$ Conferência Estadual de Cultura ligada ao SNC, onde foram escolhidos os delegados para a $2^{\mathrm{a}} \mathrm{CNC}$ que aconteceria no ano seguinte em Brasília. Desta forma, o estado de São Paulo entra com pelo menos quatro anos de atraso nas discussões sobre o sistema, o que se reflete também na implantação dos processos localmente.

São Paulo foi um dos estados que mais tarde fez sua adesão ao SNC, de acordo com informações no site do Plano Estadual. Foi o penúltimo estado do país a aderir ao SNC.

O Estado de São Paulo aderiu ao Sistema Nacional de Cultura por meio do Acordo de Cooperação Federativa firmado, em 6/9/2013, entre a União e o Governo do Estado de São Paulo, nos termos da Portaria 156 do Ministério da Cultura, de 6/12/2012. Pelo Acordo, a Secretaria de Cultura fica incumbida

3 Disponível em: http://www.saopaulo.sp.gov.br/ spnoticias/ultimas-noticias/governo-abre-inscricoes-para-conferencia-de-arte-e-cultura/ . Acesso em 07 julho 2019. 
de instituir o Sistema Estadual de Cultura, formada por nove componentes, seis obrigatórios e três optativos. ${ }^{4}$

Pouco tempo após a adesão ao SNC, a Secretaria de Estado da Cultura de São Paulo (SEC) publicou uma resolução que criou o primeiro grupo interno para a articulação da implantação do Sistema. A resolução SC 109, de 20 de dezembro de 2013 criou o Grupo de Trabalho Interno para a Discussão da Elaboração do Plano Estadual de Cultura do Estado de São Paulo. De acordo com a resolução, ao grupo composto caberia articular todas as ações iniciais de implantação do sistema paulista.

A $3^{a}$ Conferência Estadual de Cultura (CEC) (que na verdade seria a segunda) ocorrida em setembro de 2013 no Memorial da América Latina teve a participação de mais de 800 agentes do setor cultural. As propostas aprovadas na $3^{a}$ CEC paulista traz em seu texto um tom que não representava as vontades do governo estadual, mas do setor cultural local. Isso fica evidenciado no item terceiro do Eixo 1 que exige como premissa "Que o Estado aplique 3\% de seu orçamento anual na Secretaria de Cultura". Em 2013, o orçamento estadual investido na pasta da cultura não chegava aos $0,5 \%$ do PIB paulista, e nos anos que seguiram, o governo estadual declarou cortes anuais de mais de $30 \%$ de orçamento na pasta da cultura por dois anos seguidos, chegando em 2019 com um orçamento de menos de $0,3 \%$.

A primeira tentativa de inscrição do projeto de lei do Sistema Estadual Pau-

\footnotetext{
4 Informações presentes no site que abrigou a consulta pública do Plano Estadual de Cultura. O site foi retirado do ar pelo Governo do estado de SP em maio de 2019.
}

lista, nomeado como "Código Estadual de Cultura", apresentou desde o início um erro do parlamentar responsável pela inscrição da primeira proposta da lei. O Deputado Estadual Edmir Chedid (DEM - SP) inscreveu o PL relativo ao Sistema na Assembleia Legislativa do Estado de São Paulo (ALESP) em outubro de 2014 com um texto copiado da lei similar escrita no estado da Bahia. O texto inscrito no sistema legislativo estadual apresentava diversas incidências da palavra "Bahia" em trechos em que deveria constar a palavra "São Paulo". O erro foi noticiado na grande mídia local pela jornalista Monica Bergamo e o texto do PL ficou disponível no site da Assembleia Legislativa por algumas semanas. A primeira tentativa de projeto de lei do sistema paulista foi arquivada atrasando ainda mais o processo.

Por outro lado, e por iniciativa do setor cultural, um grupo de especialistas, artistas e produtores culturais assumiu a escrita das minutas para a implantação do Sistema e de seu CPF (Conselho, Plano e Fundo). A publicação da Resolução SC $n^{\circ} 85$, de 19 de agosto de 2014, revogava alguns itens da resolução 109 e visava designar membros para comporem a Comissão de Sistematização de Informações, Elaboração e Redação do Plano Estadual de Cultura do Estado de São Paulo.

A Comissão de Sistematização realizou dezenove reuniões e escreveu novas propostas para o projeto de lei do Sistema, em conjunto com os textos de implantação do Plano e do Fundo de Cultura paulista. Em março de 2015, a comissão apresentou a primeira proposta de minutas ao então Secretário de Estado da Cultura Marcelo Mattos Araújo numa reunião no prédio da secretaria para encaminhamento ao legislativo e executivo estadual. Todavia, para garantir a legitimidade da ação, a Comissão convocou uma audiência pública na Assembleia Legislativa de São Paulo, para a entrega oficial 
das minutas. A audiência foi organizada por trabalhadores da cultura paulista e por alguns parlamentares simpáticos à causa e realizada no dia 29 de abril de 2015 e contou com a presença de mais de 300 pessoas. Dentre os encaminhamentos deliberados na audiência, foi criada a Frente Pró-Sistema Estadual de Cultura, composta por diversas entidades e movimentos artísticos e culturais do estado para ampliar o debate. A Frente se propôs a liderar a luta para a implantação do Sistema Paulista em conjunto à Comissão de Sistematização, bem como pleitear a aprovação das leis do sistema com conteúdo apoiado pelos agentes da esfera em São Paulo. Composta por relevantes nomes e grupos do setor cultural, a Frente também tinha como representantes na Assembleia Legislativa os deputados estaduais: João Paulo Rillo (atualmente filiado ao Psol, mas naquele momento ainda como parlamentar do PT), Carlos Gianazzi (Psol) e Leci Brandão (PCdoB) que compunham a Frente Parlamentar de Cultura do Estado de São Paulo.

Durante um ano as minutas escritas pela Comissão de Sistematização, contendo textos sugeridos pela classe para os projetos de lei do Sistema, Plano, Fundo e Conselho estadual estiveram em análise pelo setor jurídico da Secretaria de Estado da Cultura. Entre $1^{\circ}$ de agosto e 15 de setembro de 2015, a minuta escrita pela Comissão com as metas do Plano Estadual ${ }^{5}$ ficou em consulta pública via internet num site organizado pela sociedade civil e permitiu a todos os interessados sugerirem alterações no enunciado com vistas a melhorar trechos e inserir novas metas coerentes com as demandas do setor.

Contudo, paralelo a isso e à revelia dos processos de implantação liderados

5 Idem NR 3. pelo setor cultural paulista, o Deputado Estadual Edmir Chedid retomou o processo por meio da proposta de projeto de lei do Código Estadual de Cultura com minutas diferentes das propostas pela Comissão de Sistematização com um novo texto. No dia 19 de novembro de 2015, ele esteve em reunião com o Secretário de Cultura Marcelo Araújo, conforme noticiado no site da ALESP e entregou uma nova proposta de seu PL do Código. ${ }^{6}$ Neste momento, a implantação do sistema paulista inicia um processo de mão dupla. Por um lado, o processo de implantação do Sistema estadual corria conforme os manuais de implantação do MinC determinavam, mas por outro, o processo foi "atropelado" a partir de um acordo entre os governistas estaduais.

No dia 13 de abril de 2016, numa atitude fora do contexto, Edmir Chedid em parceria com o governo inscreve na ALESP o projeto de lei N. $305^{7}$, do Código Estadual de Cultura. O texto, ao contrário do que sugere o modelo de projeto de lei de sistema de cultura, se apresenta como um compêndio de leis já existentes como o Programa de Incentivo à Cultura do Estado de São Paulo (ProAC-SP), ou mesmo a definição de datas festivas da cultura popular paulista. O Código inscrito pelo deputado do partido Democratas ignorou totalmente o teor dos enunciados produzidos pela comissão de agentes culturais e não incluiu em seu objeto principal instituir o Sistema Estadual de Cultura, muito menos um Plano Estadual de Cultura. $\mathrm{O} P L$ se inscreve à frente do processo de implantação do Sistema Paulista de Cultura ignorando as propostas escritas por pessoas do setor cultural desde 2014 com

\footnotetext{
6 Informação disponível em: http://www.al.sp. gov.br/noticia/?id=368691. Acesso em 2 jun. 2016.

$7 \quad$ PL 305/2016 disponível em: http://www.al.sp.gov. br/propositura/?id=1310397. Acesso em 2 de jun. 2019.
} 
ampla participação popular. O mesmo deputado estadual, que em 2014 havia inscrito a primeira tentativa de Sistema estadual, foi pivô de um esforço do governo do estado de São Paulo de desenvolver o processo de implantação do sistema de forma incoerente aos preceitos do SNC, sem participação popular em sua idealização e com uma estrutura diferente da sugerida pelo MinC.

Numa tentativa de barrar o texto de Edmir Chedid, o deputado estadual João Paulo Rillo, com ajuda de agentes culturais do estado, propôs no dia 21 de abril de 2016 dezesseis emendas de alteração do texto do PL do Código. As emendas foram escritas a partir das minutas desenvolvidas anteriormente pela Comissão do setor cultural e em diálogo com o enunciado do PL de Edmir Chedid. As emendas previam alterações para tornar o conteúdo do texto inscrito mais próximo às premissas das minutas escritas para o Sistema Estadual de Cultura, legitimadas nas audiências e em consulta públicas.

No dia 25 de abril de 2016, o PL de Edmir Chedid entrou para análise nas comissões da ALESP: CCJR - Comissão de Constituição, Justiça e Redação. CEC - Comissão de Educação e Cultura. CFOP - Comissão de Finanças Orçamento e Planejamento. Os últimos andamentos substanciais do PL no site da ALESP informam que:

a) Em 3 de agosto de 2016, o Deputado Marcos Zerbini (PSDB), relator da Comissão de Constituição, Justiça e Redação, deu seu parecer favorável à matéria; b) Em 13 de junho de 2018, o Deputado Luiz Turco (PT), pela Comissão de Educação e Cultura, com voto favorável ao projeto, porém contrário à emenda $n^{\circ}$ 14 e favorável às demais emendas apresentadas. Este foi contestado pelo deputado Gilmaci Santos (PRB) que pediu vistas ao projeto no dia 27 de novembro.

c) De maio a setembro de 2019, o PL foi distribuído para leitura a deputados integrantes da Comissão de Educação e Cultura da ALESP: Carlos Gianazzi (Psol), Gilmaci Santos (Partido Republicanos antigo PRB) e Professora Bebel (PT).

De outro lado, corria o processo das minutas feitas pela Comissão. Em agosto de 2016, depois de passar por várias instâncias, o então Secretário Adjunto José Roberto Sadek finalmente encaminhou para o governador parecer pedindo a aprovação do plano escrito pela comissão de sistematização. Em setembro de 2016, a Procuradoria Geral do Estado (PGE) contestou alguns pontos. A Casa Civil devolveu o documento à SEC para correção de alguns apontamentos. No mês de novembro de 2016, a SEC encaminha um novo documento à PGE, com o PL corrigido e responde as contestações. Em dezembro de 2016, o Secretário Marcelo Araújo pede exoneração do cargo e Sadek assume a cadeira interinamente, até que em março de 2017, José Luiz Penna, presidente do Partido Verde, assume a Secretaria Estadual de Cultura. Desde então, o Plano Estadual de Cultura encontra-se parado na PGE. Neste momento a secretaria alega que para dar andamento ao resgate e à atualização do Plano, seria necessário primeiramente compor o Conselho para cuidar desse processo.

A fim de acelerar o processo, em dezembro de 2017, a Secretaria Estadual de Cultura de São Paulo capitaneada por Penna, e pelo Partido Verde, preparou um decreto de instituição do Conselho Estadual de Política Cultural que seguiu para a sanção do Governador. Com a saída de Geraldo Alckmin para concorrer à eleição presidencial e a posse de seu vice-governador Márcio França, a assinatura do decreto coube a França, que não apenas assinou o decreto, mas autorizou a realização da eleição do Conselho e que de fato foi publicado em edital no Diário Oficial do estado logo após as eleições gerais 
de 2018. O edital de eleição do Conselho previa eleger 12 colegiados de 17 setores (6 titulares e 6 suplentes). Inicialmente 0 processo eleitoral estava com data marcada para acontecer no início de dezembro de 2018. Entretanto, a SEC desistiu de realizá-lo neste período e deixou para ser realizado em 2019, pela gestão seguinte, alegando falta de tempo e recursos para ampliar os locais de votação presencial.

Com a posse do novo governador João Dória em janeiro de 2019, a SEC passa a se chamar Secretaria de Cultura e Economia Criativa e este nomeia para o cargo de secretário Sérgio Sá Leitão, que entre 2017 e 2018 esteve como Ministro da Cultura de Michel Temer. No mês de fevereiro de 2019, o Secretário Sérgio Sá Leitão decide parar o processo de eleição do Conselho por vias democráticas e em reuniões com a militância do setor cultural propõe que o Conselho Estadual de Políticas Culturais seja escolhido por ele junto a entidades representativas da cultura. No dia 15 de abril de 2019, numa atitude arbitrária e contrária ao que havia sido dialogado entre representantes do setor e o secretário, o governador João Doria veicula em suas redes sociais um vídeo divulgando seu "novo" Conselho Estadual de Cultura composto por notáveis escolhidos por ele e em maioria representantes de camadas mais elitizadas e conservadoras das artes. Ainda que a militância da cultura estadual tenha buscado reverter esse quadro, exigindo que a eleição do conselho seja realizada de forma direta e que o Plano Estadual de Cultura seja tido como prioridade da pasta, até a escrita desde artigo não há indícios de que a atual gestão responda positivamente a esta reivindicação.

Outra demonstração de que a nova gestão de Dória não estava em consonância com as demandas do setor, foi o corte de dezenas de editais do ProAC, o fomento estadual, principalmente aqueles que versavam sobre a diversidade cultural como o de cultura $\mathrm{LGBT}^{8}$, cultura negra, cultura indígena, música alternativa, Hip Hop entre outros. A Secretaria alegou que isso seria uma reorganização do modelo, que até então eram 47 editais e passaram a ser apenas 31 .

No segundo semestre de 2019, o texto do Plano Estadual de Cultura de São Paulo, que foi escrito em 2015 pela comissão de trabalhadores da cultura, já conta com quatro anos de atraso e passou por diversas instâncias governamentais. Mesmo os funcionários da Secretaria não saberiam dizer qual é o texto que nesse momento ainda seria avalizado. O site da consulta pública com o histórico dos processos e com a minuta do plano foi retirado do ar em maio de 2019.

\section{A implantação do sistema de cultura na cidade de São Paulo}

A história da implantação do sistema municipal de cultura deve ser observada a partir da realização da 1a Conferência Municipal de Cultura (CMC), na gestão da então prefeita Marta Suplicy por meio do decreto municipal 44.765 de maio de 2004. A Conferência teve como tema "A cultura em São Paulo: diversidade e direitos culturais". As discussões realizadas na $1^{\text {a }} \mathrm{CMC}$ estiveram em torno de seis eixos: 1. Gestão cultural; 2. Memória e patrimônio cultural; 3. Cultura como atividade econômica; 4. Globalização e metrópole; 5 . Interfaces da cultura com a educação; 6. Cidadão e cultura. Onze pré-conferências iniciaram o processo e foram realizadas nas macro-

8 Sigla utiliza para designar a diversidade de gêneros: Lésbicas, Gays, Bissexuais e Transexuais [Nota do Editor]. 
zonas da cidade e contou com mais de 3.600 participantes. Ao todo foram contabilizadas 658 propostas da sociedade civil e a indicação de 85 representantes para a $1^{\text {a }}$ Conferência Municipal de Cultura, onde foram aprovadas 131 propostas. A Conferência foi realizada no último ano de governo de Marta Suplicy que foi sucedida por José Serra na prefeitura e que não acatou as prioridades determinadas para as políticas culturais em sua gestão.

A realização da 2a Conferência Municipal de Cultura em 2009 ocorreu durante a gestão do prefeito Gilberto Kassab. Foi organizada por uma comissão de funcionários da Secretaria Municipal de Cultura a partir do decreto municipal 50.894 de 29 de setembro de 2009. Não há registros da realização de pré-conferências territoriais. A segunda conferência não foi amplamente divulgada e contou com a presença de apenas 292 participantes. Foram elencadas 171 propostas e destas 15 foram priorizadas para levar para discussão na Conferência Estadual.

A primeira ação concreta para o início da implantação efetiva do sistema na cidade foi o decreto de 12 de junho de 2013 para a construção da $3^{a}$ CMC. A adesão do município ao SNC a partir do Acordo de Cooperação Federativa aconteceu no dia 26 de julho de 2013 já na gestão do prefeito Fernando Haddad. Nos dias 27 e 28 de julho foram realizadas as pré-conferências territoriais em cinco macrorregiões da cidade. Nos dias 2 a 4 de agosto foi realizada a terceira conferência no Memorial da América Latina com a presença de 784 participantes e aprovou 60 propostas. Destas, 30 delas foram priorizadas. A oportunidade de aderir ao SNC após duas conferências anteriores e realizar concomitantemente a conferência durante o primeiro ano da gestão de Haddad possibilitou que o processo tivesse desde o início uma organização que seguisse os trâmites sugeridos pelos manuais do SNC.
A Secretaria Municipal de Cultura de São Paulo capitaneada por Juca Ferreira foi pioneira na implantação de uma plataforma digital colaborativa para mapeamento da cultura em todo país. O desenvolvimento de um software livre pelo Instituto Tim intitulado "Mapa da Cultura" foi possível a partir de uma parceria que trazia a tecnologia não só para a cidade, mas como recurso a ser implantado posteriormente em todos os entes federados do sistema. Assim, São Paulo passou a ser um laboratório para o mapeamento da cultura, pois a plataforma SP Cultura ${ }^{10}$ passou a receber milhares de inscrições de agentes culturais, equipamentos públicos, eventos e projetos a fim de acelerar, com ajuda da sociedade civil, a contabilização dos avanços culturais na cidade.

Além da plataforma online, outro importante suporte desenvolvido pela gestão a fim de ativar a construção do Plano Municipal de Cultura (PMC) foi o desenvolvimento de publicações impressas e de distribuição gratuita. O evento "Seminário Participa Cultura: Construindo o Sistema Municipal de Cultura" ocorrido em abril de 2014 na Biblioteca Mario de Andrade foi realizado para apresentar a publicação Participação e cidadania cultural: A experiência da III Conferência Municipal de Cultura e discutir temas do sistema municipal como o projeto de lei do conselho municipal de cultura (neste momento ainda em construção) e as prioridades para o $\mathrm{PMC}$. O livro trazia relatos sobre a conferência e apresentava justificativas para as demandas municipais que deveriam servir de base para a construção do Plano. A publicação traz ainda

9 A tecnologia do Mapa da Cultura foi a partir de então utilizado em outras cidades, mas também e nível federal e nos estados.

10 Disponível em: http://spcultura.prefeitura. sp.gov.br/ . Acesso em 15 ago. 2019. 
uma ampla presença de mapas e gráficos evidenciando a diferença em termos do que acontece nas mais variadas regiões da cidade e principalmente a forte presença da questão periférica nos temas abordados. Nos dados é possível perceber que a subprefeitura da Sé apresenta o maior número de inscritos na conferência, entretanto são as diversas periferias da cidade em conjunto que apresentaram maior número de participantes. Desta forma, a participação social demarca como temática transversal os territórios, principalmente visando a inclusão da periferia da cidade nas políticas culturais de forma menos desigual. Na parte final da publicação, onde encontramos quatro textos anexos, é possível ver algumas evidências de que a periferia da cidade estava no centro das discussões. Como, por exemplo, no trecho intitulado "Pontos de vista de grupos participantes" se destaca um texto escrito pelo Fórum de Cultura da Zona Leste intitulado "A periferia foi cobrar... e agora?" onde exigem a ampliação da participação de artistas periféricos em políticas culturais já existentes e a criação de uma lei de fomento à cultura das periferias.

A construção do Plano Municipal de Cultura começou em julho de 2015 com a realização de um edital de contratação de uma empresa de consultoria para a organização das etapas seguintes. A escolhida foi a Fundação São Paulo, mantenedora da Pontifícia Universidade Católica (PUC) de São Paulo que montou uma equipe de dezoito pessoas que contava com estudiosos, gestores e trabalhadores da cultura. Aliado a isso, um chamamento público de pessoa física selecionou duas consultoras para desenvolver o diagnóstico sobre o município durante três meses a partir dos resultados iniciais vistos na terceira conferência.

Naquele mesmo período, as outras partes do sistema estavam sendo construídas no legislativo: a) 0 projeto de lei do Fundo, o PL 46/ 2013, que foi aprovado como lei 16.278/2015 (lei do Fundo Municipal de Cultura) com vistas a acelerar o processo, contrariando a sugestão dos manuais do MinC de que esta deveria ser a última etapa do sistema. b) O projeto de lei do Conselho ainda está em tramitação na Câmara Municipal como PL 01-00248/2015 (até o momento aprovada em todas as comissões e em primeira votação, mas sem perspectiva de aprovação final).

A etapa seguinte da formulação do PMC, da formulação das diretrizes, ações, metas para a consulta pública, foi realizada entre os meses de setembro e dezembro de 2015 a partir de encontros em reuniões territoriais e setoriais. Em outubro, ocorreram oficinas temáticas internas com gestores da secretaria e membros da Fundação São Paulo que organizou a etapa. Nesses encontros foi formulado o primeiro esboço do texto com as 50 metas da primeira versão do Plano Municipal de Cultura (PMC) da cidade de São Paulo visando a etapa seguinte da consulta pública. As metas foram elencadas a partir das sugestões da $3^{a} \mathrm{CMC}$ e de demandas da própria secretaria.

A consulta pública do PMC foi realizada em site específico ${ }^{11}$ entre 25 de fevereiro a 25 de março de 2016 e também em reuniões presenciais que reuniram mais de 2.500 participantes entre os dias 25 de fevereiro a 10 de março de 2016. Os encontros chamados em diferentes pontos da cidade e em reuniões temáticas setoriais abertas à sociedade civil possibilitaram uma ampliação nas discussões e no alcance dos processos. A minuta final com os textos do Plano e do sistema foi enviada para a Casa Civil no mês de ju-

11 O site foi tirado do ar pela prefeitura no ano de 2017. 
Iho, mas por conta do processo eleitoral o documento só foi oficializado pela prefeitura em novembro.

A versão final do $S M C$ e do $P M C$ com 20 metas foi publicada e lançada num grande evento no Centro Cultural São Paulo no início de dezembro de 2016. O Sistema e o Plano Municipal de Cultura de São Paulo foram aprovados por meio do decreto municipal 57.484/2016 publicado no Diário oficial da cidade de São Paulo no dia 30 de novembro de 2016. A maior parte da militância cultural presente no evento da cidade recebeu o conteúdo da versão final do plano positivamente, porém com grande preocupação por conta do atraso na oficialização e pela fragilidade de não ter sido publicado como lei.

O documento com a versão final do primeiro Plano Municipal de Cultura da cidade de São Paulo apresentava a novidade de dividir os dez anos em planos plurianuais e em eixos e metas temáticas de forma mais genérica. A relação com a estrutura de gestão da cidade, que distribui ações de todos os setores através de um plano plurianual aprovado sempre no primeiro ano de gestão de um prefeito cria assim uma forma de projetar políticas culturais para cada futuro governo. Isto é, nas metas já estava desenhada cada ação que cada nova gestão da prefeitura deveria fazer num determinado espaço-tempo e de forma descentralizada, buscando assim atingir os pontos mais distantes das periferias da cidade.

Em janeiro de 2017, a nova gestão municipal do prefeito João Dória toma posse e a SMC passa a ser capitaneada pelo Secretário André Sturm. O novo grupo político de imediato apresenta um discurso para a cultura muito diferente do anterior, e ignora a existência de um Sistema e um Plano Municipal de Cultura. Este novo tratamento com o setor cultural foi comprovado com o apagamento de mais de cinco quilômetros de murais de grafite na Avenida 23 de maio e o anúncio da privatização de centros culturais e bibliotecas já na primeira quinzena da gestão. Para reiterar isso, no início de fevereiro de 2017 anunciam na mídia o congelamento de $45 \%$ da verba destinada para a cultura aprovada na Lei Orçamentária Anual de 2017, inviabilizando boa parte dos programas já existentes e elencados no Plano de cultura da cidade. Em imediata resposta a isso, os trabalhadores e movimentos de cultura da cidade se mobilizaram e criaram a Frente Única da Cultura SP (FUC), uma iniciativa que reuniu dezenas de forças culturais das mais diversas procedências. No dia 27 de março de 2017, a partir de uma convocação da FUC, os trabalhadores da cultura da cidade realizaram uma grande manifestação pelas ruas do centro da cidade intitulada "Descongela a cultura já!" com mais de sete mil pessoas presentes e noticiada em toda a grande mídia do país. O movimento tinha como pautas únicas: o descongelamento das verbas da cultura da cidade e a imediata implantação do Plano Municipal de Cultura.

Em 31 de março de 2017, a prefeitura apresentou seu programa de metas que ignorava totalmente as propostas do PMC. As duas únicas metas para a cultura presentes no programa, que era base para o Plano Plurianual de Dória, versavam sobre a ampliação em $15 \%$ da quantidade de público em equipamentos culturais e bibliotecas.

No início de junho de 2017, após um grave incidente de ameaça de agressão a um agente cultural de uma Ocupação cultural no bairro de Ermelino Matarazzo por parte do secretário Sturm (o incidente foi gravado e divulgado maciçamente via redes sociais), dezenas de integrantes de diversos movimentos culturais ocuparam a Secretaria Municipal de Cultura exigindo a saída imediata do Secretário. A partir 
desse momento, o diálogo entre a SMC e o setor cultural passou a ser ainda mais difícil. Confrontos diários em artigos escritos nos jornais Folha de São Paulo e $O$ Estado de São Paulo, com textos de ambas as partes, deixavam ainda mais claro que o diálogo era muito difícil e que a nova gestão não estava interessada nem no Plano Municipal de Cultura e nem em permitir a participação social dos agentes culturais na construção das políticas da cidade. Ao contrário disso, a gestão propunha uma política de centralização de ações, e mostrava uma postura autoritária explicitada em polêmicas matérias de jornal e em postagens em redes sociais do próprio secretário.

No dia 16 de novembro de 2017, o Ministério Público da cidade de São Paulo abriu um inquérito para averiguar irregularidades na implantação do Plano Municipal de Cultura pela prefeitura de Dória a partir de denúncias de movimentos sociais da cultura. A denúncia feita a partir da Comissão Especial de Estudos do Orçamento da Cultura ${ }^{12}$ incluía o não cumprimento da meta 1 do PMC que prevê a execução $2 \%$ de orçamento para cultura (nesse momento executada em menos de $0,5 \%$ ) e a não execução de programas previstos no PMC e em lei, como os Fomentos ao Teatro, à Dança e à cultura da periferia.

12 A Comissão foi instituída em fevereiro de 2017 a partir de uma reivindicação da militância da cultura da cidade. Foi presidida pelo ex-presidente da Câmara o vereador Antonio Donato (PT) e contava com a presença de outros vereadores com presença regular como Toninho Vespoli (Psol), Alfredinho (PT) e Soninha (PPS). Com encontros semanais que ocorreram durante 180 dias, permitiu que trabalhadores da cultura tivessem a oportunidade de dialogar e reivindicar sobre a execução orçamentária da cidade com parlamentares e membros do executivo, principalmente das secretarias de cultura e de finanças. As pautas principais da sociedade civil que exigiu a criação da comissão eram: o descongelamento do orçamento, a melhor distribuição dos recursos pelos territórios da cidade e a imediata implantação do Plano Municipal de Cultura.
O orçamento da cultura da cidade fechou o ano de 2017 com mais de $45 \%$ de sua verba prevista na LOA não executada. A estimativa de orçamento para o ano de 2018, enviado pela SMC para o projeto de lei da Lei Orçamentária Anual (LOA), apresentou uma redução de 15\% relativa ao ano anterior. Após a realização das audiências de discussão da PLOA 2018 na Câmara de SP em dezembro de 2017, os movimentos de cultura da cidade conseguiram ampliar a margem do projeto de orçamento original, mas ainda permanecendo em pelo menos $7 \%$ menor do que o aprovado em 2017 com 0,84\% relativo ao orçamento geral da cidade. $\mathrm{O}$ foco das reivindicações dos movimentos da cultura naquele momento não era apenas pela ampliação do orçamento, mas principalmente pela implantação do Plano Municipal de Cultura.

O Plano Plurianual (PPA) de Dória, aprovado na Câmara no dia 13 de dezembro de 2017 (e que valerá até o ano de 2021), não apresentou nenhum item relativo à implantação do Plano Municipal de Cultura. Também é possível perceber no PPA que a projeção orçamentária para a Secretaria Municipal de Cultura até 2021 sofrerá redução significativa, mantendo-se nos quatro anos no patamar máximo de $0,8 \%$. Este dado contraria a Meta 1 do Plano Municipal de Cultura de São Paulo, que projeta que a cidade chegue aos $2 \%$ de verba para a cultura até $2021^{13}$. Ao contrário disso, a projeção do PPA prevê uma redução de recursos ao longo dos quatro anos de execução.

\footnotetext{
13 Projeções do PPA 2018 - 2021 para o orçamento da SMC: 2018 - R\$ 488.156.209 (0,85\% do total do orçamento); 2019 - R $\$ 469.174 .440$ (0,81\%) redução de 19 milhões; 2020 - R\$ 518.572.879 (0,82\%); 2021 - R\$ 526.387.588 (0,81\%) ampliação de apenas 8 miIhões. Informações disponíveis em http://www.camara. sp.gov.br/blog/ppa-plano-de-habitacao-e-47-projetos-de-vereadores-sao-votados/. Acesso em 15 set. 2019.
} 
Em abril de 2018, João Dória deixa a prefeitura para concorrer à eleição para o cargo de governador do estado de São Paulo e em seu lugar fica seu vice-prefeito, Bruno Covas, também do PSDB, que mantém a mesma política de cortes no orçamento para o setor cultural. Isso foi evidenciado com a proposta de Lei Orçamentária Anual municipal para o ano de 2019, que trouxe uma diminuição de mais de $18 \%$ nos recursos da cultura quando comparado ao executado no ano anterior. O decreto municipal 58.207 de 24 de abril de 2018, assinado por Covas e que versava sobre a reestruturação da Secretaria da Cultura, trazia em seu artigo 2 que as "Finalidades da Secretaria Municipal de Cultura são:

I - implementar e gerir o Sistema Municipal de Cultura;

II - implementar, coordenar, monitorar e avaliar o Plano Municipal de Cultura - PMC;"14

Contudo, mesmo com este decreto, a gestão continuou ignorando o Plano Municipal de Cultura, tanto em seus documentos oficiais, quanto nos diálogos com os trabalhadores da cultura. A justificativa versa sobre a falta de recursos e a falta de funcionários para a implantação do Plano.

Em janeiro de 2019, o prefeito Covas exonerou André Sturm da Secretaria Municipal de Cultura e em seu lugar nomeou o empresário Alexandre Yousseff, que em suas declarações iniciais na imprensa não mencionou o Plano Municipal de Cultura, nem mesmo a maioria dos pro-

\footnotetext{
14 Disponível em: https://leismunicipais.com. br/a/sp/s/sao-paulo/decreto/2018/5820/58207/decreto-n-58207-2018-dispoe-sobre-a-reorganizacao-da-secretaria-municipal-de-cultura-altera-a-denominacao-e-a-lotacao-dos-cargos-de-provimento-em-comissao-que-especifica-bem-como-transfere-cargos-para-o-quadro-especifico-de-cargos-de-provimento-em-comissao. Acesso em 17 set. 2019.
}

gramas municipais existentes há muitos anos e estabelecidos em leis.

Em 12 de março de 2019, o Movimento Cultural das Periferias (MCP) ${ }^{15}$ realizou uma grande audiência cidadã da cultura no teatro Cia Pessoal do Faroeste no bairro da Luz, com a presença do secretário e sua equipe e de mais de 300 pessoas da sociedade civil. Nesta audiência, integrantes do MCP apresentaram uma série de dados e reivindicações, entre elas a imediata implantação do Plano Municipal de Cultura de São Paulo e a criação de uma Comissão de Política Cultural da Periferia, para trabalhar em conjunto com a SMC e com o legislativo a fim de retomar os processos de implantação do Sistema Municipal de Cultura. A primeira ação concreta para isso foi a criação de uma subcomissão do Plano Municipal de Cultura no mês de maio de 2019, submetida à Comissão de Finanças e Orçamento ${ }^{16}$.

Em setembro de 2019, a subcomissão realizou o Seminário Plano Municipal de Cultura na Câmara Municipal de São Paulo, com cinco mesas temáticas a fim de trazer de volta as discussões sobre o tema e chamar a atenção da prefeitura e trabalhadores do setor. Até o momento, a prefeitura de São Paulo continua ignorando o Plano Municipal de Cultura não incluindo nenhum processo do sistema em seus planos. 15 O Movimento Cultural das Periferias surgiu em
2013 com a intenção de democratizar e descentralizar
recursos para os trabalhadores da cultura das periferias
da cidade. O movimento criou e viabilizou a lei $16.496 / 16$
que busca financiar projetos culturais realizados na peri-
feria da cidade.

16 A subcomissão, assim como a Comissão especial implantada em 2017, visa a fiscalização, análise e atualização do PMC, bem como a inserção de itens orçamentários na Lei Orçamentária Anual da cidade para 2020 com vistas a regionalizar e descentralizar os recursos para que estes cheguem de fato às periferias da cidade. 


\section{Considerações finais}

Nos dois casos observados, foi possível afirmar sobre a falta de interesse político de gestores de um mesmo partido, o PSDB, na implantação dos sistemas de cultura tanto em âmbito estadual quanto municipal. Destaque para o desmonte ocorrido na gestão Dória na prefeitura no ano de 2017 (e depois refletido no governo dele no estado em 2019) visível principalmente na falta de diálogo com o setor cultural. Isso também se estende à não implantação do Plano Municipal de Cultura como um todo, um documento criado com ampla participação popular e que atravessou mais de dez anos de discussões. Ao contrário disso, as duas gestões de Doria têm se empenhado em encerrar programas e cortar verbas de políticas culturais que existem há décadas como os Fomentos (Teatro, Dança e os recentes Circo e Periferia), e o Programa Vai em nível municipal. Na atual gestão no estado, Doria e o Secretário Sá Leitão cortam os editais que promoviam a diversidade cultural no ProAC em plano estadual. Relevante destacar que a gestão também barrou processos de implantação dos sistemas, ao ignorar a existência do Plano Municipal de Cultura da cidade ou mesmo ao não acatar o decreto que tratava da eleição direta do Conselho estadual, nomeando pessoalmente um grupo de notáveis que o apoiavam.

Os dois processos relatados, tanto no estado quanto no município de São Paulo, demonstram a dificuldade de implantação de sistemas de cultura territoriais durante gestões que não comungam com os mesmos preceitos de política cultural previstos no Sistema Nacional de Cultura. Da mesma forma é possível dizer que a não vontade política é sempre justificada pela falta de recursos e equipes nas secretarias. A falta de diálogo entre os agentes públicos e o setor cultural ocorreu de forma muito similar nos dois entes federados em momentos que esse mesmo grupo político estava no governo.
Contudo, é relevante perceber que a participação popular a partir de movimentos organizados de trabalhadores da cultura tem desempenhado um importante papel na contenção do desmonte dessas políticas nesses territórios. Ainda que em boa parte dos casos tenha sido impossível segurar as ações governamentais empenhadas a não permitir a concretização dessas políticas, os movimentos conseguiram ao menos uma redução de danos e demonstraram a importância do engajamento político na luta pela manutenção de direitos adquiridos.

\section{Referências}

CORÁ, Maria Amélia Jundurian; CÓRDULA, Américo. Participação social na elaboração do Plano Municipal de Cultura de São Paulo/SP. In: BARROS, José Marcio; COSTA, Katia (org.). Planos municipais de cultura: reflexões e experiências. Belo Horizonte: EdUEMG, 2019.

QUEIROZ. Inti Anny. A arquitetônica da esfera político-cultural brasileira nos enunciados do Sistema Nacional de Cultura. Doutorado em Filologia e Língua Portuguesa. 2019. Disponível em: http://www.teses.usp.br/teses/disponiveis/8/8142/tde-15082019093817/pt-br.php. Acesso em 14 set. 2019.

SÃO PAULO. PROJETO DE LEI N. 305 de abril de 2016, que institui o Código Estadual de Cultura. Informação disponível em: http://www.al.sp.gov.br/ propositura/?id=1310397. Acesso em 02 set. 2019.

SECRETARIA MUNICIPAL DE CULTURA DE SÃO PAULO. Plano Municipal de Cultura. São Paulo: SMC, 2016a.

SECRETARIA MUNICIPAL DE CULTURA DE SÃO PAULO. Plano Municipal de Cultura: caderno de consulta pública. São Paulo: SMC, 2016b.

SECRETARIA MUNICIPAL DE CULTURA DE SÃO PAULO. Participação e cidadania cultural: a experiência da III Conferência Municipal de Cultura de São Paulo. Organizadoras: Ana Paula do Val; Luciana Piazzon Lima; Maria Vasconcelos Oliveira; Viviane Cristina Pinto. São Paulo: SMC, 2014. 